\title{
Persistence of infectious hepadnavirus in the offspring of woodchuck mothers recovered from viral hepatitis
}

\author{
Carla S. Coffin ${ }^{1}$ and Tomasz I. Michalak ${ }^{1,2}$ \\ ${ }^{1}$ Molecular Virology and Hepatology Research, Division of Basic Medical Sciences, and \\ ${ }^{2}$ Division of Pathology, Faculty of Medicine, Health Sciences Centre, Memorial University of Newfoundland, St. John's, \\ Newfoundland A1B 3V6, Canada \\ Address correspondence to: Tomasz I. Michalak, Molecular Virology and Hepatology Research, Division of Basic Medical Sciences, \\ Faculty of Medicine, Memorial University of Newfoundland, St. John's, Newfoundland A1B 3V6, Canada. Phone: (709) 737-7301 \\ or (709) 737-7214; Fax: (709) 737-2228; E-mail: timich@morgan.ucs.mun.ca.
}

Received for publication August 26, 1998, and accepted in revised form June 15, 1999.

\begin{abstract}
Mother-to-child transmission is an important route for hepatitis B virus (HBV) dissemination. It has been established that HBV traces persist for years after complete clinical recovery from hepatitis $B$. Similarly, resolution of hepatitis caused by HBV-related woodchuck hepatitis virus (WHV) is followed by occult lifelong carriage of pathogenic virus. In this study, we documented that WHV persisting after termination of acute hepatitis is transmittable to newborns as an asymptomatic long-term infection. All 11 offspring from 4 dams studied carried transcriptionally active WHV genomes for 3.5 years after birth without immunovirological markers of infection. WHV genomes and mRNA were detected both in the liver and lymphoid tissue in the majority of offspring; WHV covalently closed circular DNA was detected in some samples. In 4 offspring, however, the virus was restricted to the lymphatic system. In the circulation, WHV DNA-reactive particles were DNase resistant and of comparable size and density to complete virions. Importantly, the virus in offspring with or without hepatic WHV DNA expression was infectious to WHV-naive woodchucks. Finally, offspring challenged with WHV were not protected against reinfection. These findings show that mothers with occult hepadnaviral carriage transmit pathogenic virus to their offspring, inducing a persistent infection invariably within the lymphatic system but not always in the liver.
\end{abstract}

J. Clin. Invest. 104:203-212 (1999).

\section{Introduction}

Mother-to-child transmission of hepatitis B virus (HBV) is an important mechanism by which the virus is spread within the human population, especially in areas with high incidence of hepatitis B (1). The majority of infants born to mothers with serologically evident HBV infection become chronic HBV carriers, with readily detectable virus DNA and viral surface antigen (HBsAg) in the circulation. These persons are infectious to healthy individuals and are at significant risk for the development of hepatocellular carcinoma (2). Recent studies have documented that years after their complete clinical and serological recovery from acute hepatitis B, apparently healthy individuals persistently carry low levels of HBV detectable by molecular assays, often despite the presence of potentially neutralizing antiviral antibodies and a vigorous, polyclonal virus-specific cytotoxic T-lymphocyte response (3-8). It is highly possible that blood and organ donations from individuals with this occult, serologically concealed infection could transmit HBV to virus-naive recipients (9-11). The persistence of HBV traces could also be important in reactivation of infectious virus due to immunosuppression $(12,13)$. Furthermore, the possibility exists that integration of HBV DNA sequences into hepatocyte genomes may contribute to pathogenesis of hepatocellular carcinoma (14-16). This tumorigenic process may progress in the absence of serological indicators of HBV infection (14).

Woodchuck hepatitis virus (WHV) infection of the eastern American woodchuck (Marmota monax) has been validated as a valuable model for the study of the natural course, pathogenesis, and pathological implications of HBV infection $(17,18)$. The most recent findings showed that exposure to WHV, resulting in an episode of acute hepatitis ( $\mathrm{AH})$ with subsequent complete serological recovery, is followed by lifelong persistence of traces of infectious virus (19). Virus replication is sustained both in the liver and lymphatic system of these carriers. Inocula derived from convalescent animals induce typical AH in virus-naive woodchucks, indicating that biologically competent hepadnavirus persists for life in these apparently healthy animals.

In the present study, we hypothesized that hepadnavirus carried by mothers as an occult infection can be transmitted to their offspring. To investigate this possibility, we examined woodchuck offspring born in captivity to dams convalescent from WHV hepatitis. The specific objectives of this investigation were to determine whether vertical transmission of the hepadnaviral genome from convalescent mothers to their offspring is taking place and, if so, to identify tissue reservoirs of virus replication, to characterize physicochemical properties of particles carrying WHV DNA, and to establish whether the virus carried by the offspring is infectious. Our results show that such mothers transmit WHV to newborns as an asymptomatic, serologically undetectable infection that persists for years after birth. In the majority of the offspring, WHV occurred both in the 
liver and lymphoid cells, although in some cases, virus sequences were exclusively detected in the lymphatic system. Importantly, the carried WHV DNA-reactive particles displayed physicochemical properties of complete WHV virions and were infectious to naive animals.

\section{Methods}

Maternal woodchucks and their offspring. The offspring of 4 woodchucks with complete serological recovery from an episode of WHV hepatitis were investigated (Table 1). Three maternal woodchucks (A, B, and C) were inoculated intravenously with WHV as juveniles, whereas the fourth (D) was exposed to WHV under undetermined conditions before arrival at our colony. All inoculated animals developed a typical self-limiting episode of $\mathrm{AH}$. Resolution of AH was diagnosed when serum WHV surface antigen (WHsAg) permanently cleared and antibodies against WHsAg (anti-WHs) appeared. These 3 animals were part of a study aimed at the determination of the longevity and pathological consequences of occult WHV persistence acquired after resolution of $\mathrm{AH}$, and they were the only animals in the study cohort that produced offspring (19). All of them carried WHV DNA traces and antibodies to WHV core antigen (anti-WHc) throughout their life-span. The fourth maternal woodchuck (D) was reactive for serum WHV DNA and antiWHc but negative for WHsAg and anti-WHs at arrival. This animal cleared anti-WHc 7 weeks before giving birth. Two liver biopsies obtained at 9.5 and 8 months before parturition showed normal liver morphology. Therefore, although female D was evidently infected with WHV in the past, it completely resolved hepatitis and remained an asymptomatic carrier of WHV DNA.

Three male (M) and 8 female $(\mathrm{F})$ offspring were studied (Table 1). Maternal woodchucks $\mathrm{A}$ and $\mathrm{C}$ gave birth to 1 female offspring each (1A/F and $5 \mathrm{C} / \mathrm{F}$, respectively) $\sim 5$ months after anti-WHs appearance. Female B had 1 female $(2 \mathrm{~B} / \mathrm{F})$ and 2 male offspring $(3 \mathrm{~B} / \mathrm{M}$ and $4 \mathrm{~B} / \mathrm{M})$ born 6 months after first detection of anti-WHs. Animal $\mathrm{D}$ produced 1 male $(8 \mathrm{D} / \mathrm{M})$ and 5 female babies $(6 \mathrm{D} / \mathrm{F}$, $7 \mathrm{D} / \mathrm{F}, 9 \mathrm{D} / \mathrm{F}, 10 \mathrm{D} / \mathrm{F}$, and $11 \mathrm{D} / \mathrm{F}$ ) after a 10 -month carriage of WHV DNA traces. Five offspring were autopsied during the study (Table 1).

Sample collection. Beginning at 2 months of age and continuing up to 42 months after birth, blood was collected monthly for isolation of serum or plasma and PBMCs. PBMCs were harvested on Histopaque-1119 (Sigma Chemical Co., St. Louis, Missouri, USA) gradients as described previously (20). In offspring observed for longer than 6 months, liver biopsies were done annually by laparotomy. In the case of autopsy $(2 \mathrm{~B} / \mathrm{F}, 3 \mathrm{~B} / \mathrm{M}, 5 \mathrm{C} / \mathrm{F}$, and $6 \mathrm{D} / \mathrm{F}$ ), serum, PBMCs, samples from liver and lymphoid organs (spleen, bone marrow, lymph nodes, and, occasionally, thymus), and skeletal muscle were collected. For $1 \mathrm{~A} / \mathrm{F}$, liver, spleen, thymus, and lymph nodes, but not serum, were available for investigation. In some autopsy cases, splenocytes containing mainly lymphocytes were isolated (21).

Serological assays and WHV DNA slot-blot bybridization. WHsAg was assayed by an RIA with a sensitivity for the detection of purified WHsAg of $3.25 \mathrm{ng} / \mathrm{mL}$ (22). AntiWHs was measured using a cross-reactive ELISA (Ausab
EIA; Abbott Laboratories, North Chicago, Illinois, USA). Anti-WHc was determined by a specific competition ELISA (19). Slot-blot hybridization for WHV DNA was performed using $50 \mu \mathrm{L}$ of serum blotted onto a nylon membrane (Hybond N; Amersham Life Sciences Inc., Arlington Heights, Illinois, USA) by microfiltration and using ${ }^{32} \mathrm{P}$-labeled full-length, linearized, recombinant WHV DNA as a probe (23). Sensitivity of the assay is $10^{6}-10^{7}$ viral genome equivalents per milliliter (vge/mL).

DNA extraction, and WHV DNA and covalently closed circular DNA PCR amplifications. DNA from $50 \mu \mathrm{L}$ of serum and $1 \mu \mathrm{g}$ DNA from PBMCs, splenocytes, or tissue samples, isolated by digestion with proteinase $\mathrm{K}$ and a standard extraction procedure (4), were amplified by PCR using primers and conditions described previously (19). Three sets of direct and nested oligonucleotide primer pairs specific for 3 nonoverlapping regions of WHV DNA core (C), envelope (S), and X genes were used. Direct amplification of the WHV C gene sequences was done with primers PCNV (1983-2007) (numbers denote the position of the sequence in WHV genome according to ref. 24; GenBank accession no. M11082) and COR (2586-2602), whereas PPCC (2033-2049) and CCOV (2439-2460) primers were used for the nested PCR. To amplify WHV $S$ gene sequences, primers PSW (2947-2966) and SUW (894-917) for the direct PCR, and primers NSW (303-322) and SSW (781-803) for the nested PCR, were used. WHV X subgenomic fragments were amplified with primers PXO (1522-1547) and XPC (1891-1907) and then, if required, with nested primers PXX (1568-1584) and XXC (1742-1760). For detection of WHV covalently closed circular DNA (cccDNA), 2-5 $\mu \mathrm{g}$ of DNA was digested in $20-\mu \mathrm{L}$ volume with $1 \mu \mathrm{L}$ of mung bean nuclease $(40 \mathrm{U} / \mu \mathrm{L})$ and $2 \mu \mathrm{L}$ of $10 \times$ mung bean digestion buffer (both from GIBCO BRL, Grand Island, New York, USA) under conditions established by others (25). PCR on digested DNA $(1.0-2.5 \mu \mathrm{g})$ was done using primers spanning the WHV gap region PGAP1 (5'TGGTGTGCTCTGTGTTTGCTGACGC; 1298-1322) and MCOR (5'-CCGGAAGAGTCGAGAGAATGGGTGC; 2453-2429), followed, if required, by nested PCR with primers XINT (5'-CTTCGCCTTCGCCCTCAGACGAGT; 1630-1653) and CCCV (5'-GTCCCCAGGTGTCAGTGACA; 2303-2284) under cycling conditions: $95^{\circ} \mathrm{C}$ for 5 minutes, $56^{\circ} \mathrm{C}$ for 2 minutes, and $72^{\circ} \mathrm{C}$ for 3 minutes, followed by 30 cycles of $95^{\circ} \mathrm{C}$ for 1 minute, $56^{\circ} \mathrm{C}$ for 1 minute, $72^{\circ} \mathrm{C}$ for 1 minute, and, finally, $72^{\circ} \mathrm{C}$ for 15 minutes. Extensive precautions were taken during sample collection, DNA isolation, and PCR to eliminate any potential viral and DNA contamination, as described in detail previously (19). Mock samples containing TE buffer (1 mM EDTA in $10 \mathrm{mM}$ Tris-HCl $[\mathrm{pH}$ 8.0]) instead of DNA were extracted and treated precisely as test DNA and used as negative control. DNA extracted from sera, PBMCs, and livers of healthy and WHV-infected animals was used as negative and positive controls, respectively. The final PCR contamination control consisted of water added instead of DNA to the PCR mixture. Southern blot analysis of the final PCR products was used to verify virus sequence detection and validity of controls.

WHV DNA sequencing. In selected cases, the full-length 
WHV DNA was amplified with primers PPC1 (1908-1926) and XPC (1891-1907) located at the WHV nick region, using the Expand High Fidelity PCR System (Roche Diagnostics, Laval, Quebec, Canada) and conditions described previously (19). When required, complete WHV DNA was further amplified with WHV C (pair PCNV-COR) and S (pair PSW-SUW) gene-specific primers. PCR products were sequenced using the fmol DNA Sequencing System (Promega Corp., Madison, Wisconsin, USA) and WHV-specific primers: PPC1(1908-1936), QC02 (5'CTC GGATCCCTATAAAGAATTTGG; 2026-2049), QC03 (5'-ACTTTCGGACAACATACAG; 2344-2363), QCS5 (5'-CCATATTCTTGGGAACACAG; 2952-2971); QS06 (5'CCTGGGCCTATAATAGTT; 3298-3315), QS07 (5'-CATCAAGTCTCCTAGGACTC; 303-322), and QS08 (5'-CCTGTCTGTCCTCTTCAACCC; 602-622).

$R N A$ extraction and RT-PCR. A total of $1 \mu \mathrm{g}$ of total RNA isolated from tissue or PBMCs using Trizol reagent (GIBCO BRL) was reverse transcribed to complementary DNA (cDNA), as described before (19), and was PCR amplified with WHV C or WHV S gene primers. Each reaction was set up in parallel with a negative control that had all the ingredients except RT (aliquot $\mathrm{RT}^{-}$), a positive control consisting of total RNA isolated from the liver, spleen, or PBMCs of a WHsAgpositive WHV carrier. The specificity of the amplified WHV cDNA sequences and the validity of the RT and PCR contamination controls were ascertained by Southern blot analysis.

Detection of amplified WHV DNA. PCR products were analyzed by agarose gel electrophoresis and Southern blotting with ${ }^{32} \mathrm{P}-$ labeled full-length WHV DNA as described (19). For estimation of WHV DNA levels, autoradiographical or phosphor images of hybridization signals were analyzed for equivalence with 10 -fold serial dilutions of complete recombinant WHV DNA, using a Canberra-Packard computerized imaging system (Canberra-Packard Canada Ltd., Mississauga, Ontario, Canada).

Analysis of physicochemical properties of particles carrying WHV DNA. For determination of sedimentation velocity, $100 \mu \mathrm{L}$ of serum obtained from $4 \mathrm{~B} / \mathrm{M}$ offspring at 32 months after birth and from $7 \mathrm{D} / \mathrm{F}$ offspring at 22 months of age (at the time when their livers were WHV DNA positive and negative, respectively) was centrifuged through $4.5 \mathrm{~mL}$ of $15 \%$ (wt/vol) sucrose in TN buffer $(140 \mathrm{mM} \mathrm{NaCl}$ in $10 \mathrm{mM}$ Tris- $\mathrm{HCl}[\mathrm{pH} 8.0]$ ) layered onto a $0.5-\mathrm{mL} 60 \%$ sucrose cushion $(4,19)$. Samples of purified WHV virions (26) and recombinant WHV DNA digested with restriction enzyme $M n l$ I were centrifuged in parallel. After centrifugation at 200,000 $\mathrm{g}$ for 4 hours at $5^{\circ} \mathrm{C}$ in an SW50.1 rotor (Beckman Instruments Inc., Palo Alto, California, USA), fractions of $340 \mu \mathrm{L}$ were collected from the bottom of each tube. DNA extracted from $100 \mu \mathrm{L}$ of each fraction was tested for WHV DNA by PCR with WHV C or WHV S gene-specific primers. To determine the presence of envelope-protected particles, $100 \mu \mathrm{L}$ of WHV DNA-reactive fractions was supplemented with $10 \mu \mathrm{L}$ of DNase digestion buffer $(100 \mathrm{mM}$ $\mathrm{MgCl}_{2}$ in $500 \mathrm{mM}$ Tris- $\left.\mathrm{HCl}[\mathrm{pH} 8.0]\right)$ and $5 \mu \mathrm{L}$ of DNase $\left(1 \mathrm{mg} / \mathrm{mL}\right.$; activity $20 \times 10^{3}$ to $50 \times 10^{3} \mathrm{U} / \mathrm{mL}$; deoxyri- bonuclease I; Roche Diagnostics) and was incubated for 1 hour at $37^{\circ} \mathrm{C}$. DNA was extracted from the resulting digest and analyzed by PCR.

To determine the buoyant density of WHV DNA-reactive particles, $200 \mu \mathrm{L}$ of sera collected at 32 months after birth from 4B/M, a culture supernatant obtained after LPS stimulation of PBMCs collected from the same animal at 32-34 months of age, and serum from $7 \mathrm{D} / \mathrm{F}$ obtained at 22 months after birth were layered separately onto $5-\mathrm{mL}$ continuous gradients of $1.1-1.7 \mathrm{~g} / \mathrm{cm}^{3} \mathrm{CsCl}$ (Sigma Chemical Co.) in TE buffer. A total of $200 \mu \mathrm{L}$ of purified WHV virions was centrifuged under the same conditions. After centrifugation at $200,000 \mathrm{~g}$ for 18 hours at $10^{\circ} \mathrm{C}$ in a Beckman SW50.1 rotor, $400 \mu \mathrm{L}$ of fractions was collected from the bottom of each tube and evaluated for $\mathrm{CsCl}$ density. A total of $100 \mu \mathrm{L}$ of fractions 1-13 was used for DNA extraction and tested for WHV DNA by PCR using WHV C gene-specific primers. Evaluation of WHV DNA expression in PBMCs after cell surface digestion with DNase and trypsin. To determine whether WHV DNA detected in offspring PBMCs was of an intracellular origin or resulted from the carryover of WHV virions or DNA on the cell surface, viable PBMCs $(\sim 3 \times$ $10^{7}$ cells $/ \mathrm{mL}$ ) collected from $4 \mathrm{~B} / \mathrm{M}$ at 40 months after birth and from a WHsAg-positive chronic carrier were digested with DNase and trypsin as described previously (19). DNA was then extracted from enzyme-treated and untreated PBMCs as well as from the final cell washes obtained before and after PBMC digestion. Each sample was tested for WHV DNA by PCR.

Determination of the effect of mitogen stimulation on WHV transcription in offspring PBMCs. Approximately $2 \times$ $10^{6} / \mathrm{mL}$ PBMCs were cultured for 72 hours at $37^{\circ} \mathrm{C}$ with $10 \mu \mathrm{g} / \mathrm{mL} \mathrm{LPS} \mathrm{or} 5 \mu \mathrm{g} / \mathrm{mL}$ concanavalin A (ConA) using conditions described previously (21). In parallel, $\sim 2 \times 10^{7}$ nonstimulated cells from the same isolation were saved and used as a control. PBMCs obtained at 33.5 months after birth from $10 \mathrm{D} / \mathrm{F}$ and $11 \mathrm{D} / \mathrm{F}$ were stimulated with LPS, whereas PBMCs isolated at 34.5 months after birth were stimulated with ConA. In addition, PBMCs from 4B/M harvested at 32, 33.5, and 34 months of age were cultured with LPS, whereas those obtained at 33 months after birth were cultured with ConA. After a 72-hour culture, cells were pelleted at 400 $g$ for 10 minutes, and the supernatant was saved. The cells were washed with $15 \mathrm{~mL}$ of RPMI-1640 medium and pelleted again. The final cell pellet, along with the pellet of nonstimulated cells, was extracted using Trizol reagent to isolate total RNA. For $4 \mathrm{~B} / \mathrm{M}$, both the final cell wash recovered before culture and PBMC culture supernatant collected after 72 hours of mitogen stimulation ( $\sim 9.0 \mathrm{~mL}$ each) were centrifuged at 140,000 $g$ for 18 hours using a Beckman SW40 rotor. The pellets were suspended in $1 \mathrm{~mL}$ of sterile $0.9 \% \mathrm{NaCl}$ solution. DNA was extracted from $100 \mu \mathrm{L}$ of each suspension and tested for WHV DNA by PCR, using WHV C and S gene primers. The remaining $900 \mu \mathrm{L}$ of the PBMC culture supernatant was injected into a WHV-naive woodchuck (see below).

Determination of the infectivity of WHV persistently carried by the offspring. Nine-milliliter samples of sera or plasma collected from 3B/M during autopsy at 15 months after 
Table 1

Serological features of WHV infection and WHV DNA detection in maternal woodchucks convalescent from viral hepatitis and in their offspring

\begin{tabular}{|c|c|c|c|c|c|c|c|}
\hline \multicolumn{8}{|c|}{ Animal } \\
\hline \multirow[t]{2}{*}{ Mother } & Offspring (M/F) & Observation period & Duration of WHs antigenemia & Anti-WHs ${ }^{A}$ & Anti-WHc ${ }^{A}$ & \multicolumn{2}{|c|}{ WHV DNA in final sample ${ }^{A}$} \\
\hline & & Months & Months & & & & Months ${ }^{B}$ \\
\hline A & & $11^{\mathrm{C}}$ & 1 & + & + & + & \\
\hline & $1 \mathrm{~A} / \mathrm{F}^{\mathrm{D}}$ & 1 & NA & NA & NA & NA & \\
\hline B & & $9^{c}$ & 1 & + & + & + & \\
\hline & $2 \mathrm{~B} / \mathrm{FD}^{\mathrm{D}}$ & 4 & - & - & - & + & 4 \\
\hline & $3 \mathrm{~B} / \mathrm{M}^{\mathrm{D}}$ & 15 & - & - & - & + & 15 \\
\hline & $4 \mathrm{~B} / \mathrm{M}$ & 42 & - & - & - & + & 42 \\
\hline C & & $6^{\mathrm{C}}$ & + & + & + & + & \\
\hline & $5 \mathrm{C} / \mathrm{F}^{\mathrm{D}}$ & 22 & - & - & - & + & 22 \\
\hline D & & $10^{C}$ & - & - & + & + & \\
\hline & $6 \mathrm{D} / \mathrm{F}^{\mathrm{D}}$ & 31 & - & - & - & + & $23^{\mathrm{E}}$ \\
\hline & $7 \mathrm{D} / \mathrm{F}$ & 42 & - & - & - & + & $23^{\mathrm{E}}$ \\
\hline & $8 \mathrm{D} / \mathrm{M}$ & 42 & - & - & - & + & $30^{\mathrm{F}}$ \\
\hline & $9 \mathrm{D} / \mathrm{F}$ & 42 & - & - & - & + & $30^{\mathrm{F}}$ \\
\hline & $10 \mathrm{D} / \mathrm{F}$ & 42 & - & $30^{\mathrm{G}}$ & - & + & 42 \\
\hline & $11 \mathrm{D} / \mathrm{F}$ & 42 & - & - & - & + & 42 \\
\hline
\end{tabular}

AIn samples collected before challenge with infectious WHV. ${ }^{\mathrm{B} O f f s p r i n g ~ a g e ~ i n ~ m o n t h s ~ a t ~ s a m p l e ~ c o l l e c t i o n . ~}{ }^{\mathrm{C} B e f o r e}$ parturition. ${ }^{\mathrm{D}} \mathrm{Autopsied}$ animals. ${ }^{\mathrm{E}} \mathrm{Offspring}$ challenged with WHV at 23 months after birth. FOffspring challenged with WHV at 30 months after birth. ${ }^{G}$ Before this study, this offspring was challenged at the age of 5 months with culture supernatant from LPS-stimulated PBMCs from an adult woodchuck convalescent from $\mathrm{AH}$ (containing $\sim 3 \times 10^{3} \mathrm{WHV}$ genome equivalents), and produced periodically detectable anti-WHs without evidence of active WHV infection. NA, not applicable (no sera available for testing).

birth, 4B/M at 32-34 months after birth, and 7D/F at 11-22 months after birth were centrifuged at $200,000 \mathrm{~g}$ for 18 hours using a Beckman SW50.1 rotor. The pellet from each sample was suspended in $1 \mathrm{~mL}$ sterile water, and 100 $\mu \mathrm{L}$ was tested for WHV DNA by PCR/Southern blotting. This analysis showed that the samples, as well as concentrated culture supernatant from 4B/M PBMCs, contained WHV genomes ranging between $10^{2}$ and $10^{3}$ vge $/ 100 \mu \mathrm{L}$. The remaining $900 \mu \mathrm{L}$ of each sample was intravenously injected into a WHV-naive, healthy woodchuck. Thus, an inoculum derived from serum of $3 \mathrm{~B} / \mathrm{M}$ was administered into $260 / \mathrm{M}$, and inocula prepared from $7 \mathrm{D} / \mathrm{F}$ and $4 \mathrm{~B} / \mathrm{M}$ plasma were administered into $276 / \mathrm{F}$ and $269 / \mathrm{F}$, respectively. In addition, a WHV-naive 278 /F was intravenously injected with $900 \mu \mathrm{L}$ of concentrated culture supernatant from LPS-stimulated PBMCs of $4 \mathrm{~B} / \mathrm{M}$, prepared as already described here. Animals 260/M and 276/F were sacrificed at 110 and 79 days after inoculation, respectively, whereas autopsy of 269/F and 278/F was performed at 215 and 218 days after inoculation, respectively. Sequential sera and PBMCs, as well as liver tissue samples obtained $\sim 2$ months before and 2.5 months after inoculation and at autopsy, were tested for WHV DNA by PCR. Sera or plasma were also tested for WHsAg, anti-WHc, anti-WHs, and liver tissue evaluated by histology.

Determination of offspring susceptibility to WHV. 6D/F and $7 \mathrm{D} / \mathrm{F}$ offspring at 23 months after birth, and $8 \mathrm{D} / \mathrm{M}$ and $9 \mathrm{D} / \mathrm{F}$ at 30 months of age, were injected intravenously with $1.1 \times 10^{10} \mathrm{DNase}$-protected WHV genome equivalents (19) derived from sera of a single WHsAg-positive chronic WHV carrier. Sera from these offspring were collected biweekly for 3 months after inoculation and then monthly; they were then tested for WHsAg, anti-WHs, anti-WHc, and WHV DNA.

Histological analysis of liver disease. Tissue fragments fixed in $10 \%$ buffered formalin were conventionally processed and embedded in paraffin. Paraffin sections $(4 \mu \mathrm{m})$ were stained with hematoxylin and eosin, Masson's trichrome, or periodic acid-Schiff or were impregnated with silver. Assessment of liver injury was based on criteria described previously (26).

\section{Results}

Mothers convalescent from viral hepatitis transmit serologically silent WHV infection to their offspring. Sera collected from offspring born to woodchuck dams with complete serological recovery from WHV hepatitis were nonreactive for WHsAg, anti-WHs, and anti-WHc, yet they persistently carried traces of WHV genomes (Table 1). Thus, the sera were negative for WHV DNA by slot-blot hybridization (sensitivity: $10^{6}-10^{7} \mathrm{vge} / \mathrm{mL}$ ) and direct PCR when the amplified products were analyzed in ethidium bromide agarose (sensitivity: $10^{4} \mathrm{vge} / \mathrm{mL}$ ). Examination of the same sera by nested PCR with WHV DNA-specific primers, followed by detection of the amplified sequences by Southern blot hybridization (sensitivity: $10-10^{2} \mathrm{vge} / \mathrm{mL}$ ), demonstrated WHV DNA up to the end of reported follow-up (Table 1). Figure 1 illustrates detection of WHV DNA in sera collected during the 3-year observation of $4 \mathrm{~B} / \mathrm{M}$. The same was true when PBMCs from offspring were analyzed using the same detection system (approximate sensitivity: 0.05 WHV DNA vge/104 cells). In summary, for offspring observed for longer than 6 months, both sera and PBMCs were found to be reactive for WHV DNA, using 2 subsequent rounds of PCR amplification with $\mathrm{C}, \mathrm{S}$, and/or $\mathrm{X}$ gene primers at mean intervals of 3.2 months \pm SD 1.4 and 3.8 months \pm SD 1.1 for serum and PBMCs, respectively. In addition, the detection of a particular WHV gene sequence varied in serum, PBMCs, and liver biopsy samples obtained at the same time point of follow-up (data not shown). This shows that to exclude definitively the presence of low quantities of hepadnavirus, it is advisable to amplify DNA from different sites of possible virus occurrence 


\section{Figure 1}

Detection of WHV DNA in serial serum samples from 4B/M offspring. Sera collected between 2 and 36 months after birth were tested for WHV DNA by nested PCR using WHV C, S, and X gene-specific primers, and the amplified products were analyzed by Southern blot hybridization to recombinant WHV DNA probe. DNA isolated from serum of a WHsAgpositive chronic carrier and water were used as positive control and negative control, respectively. Positive samples show the expected sizes (bp) of the amplified nucleotide fragments noted by arrowheads.

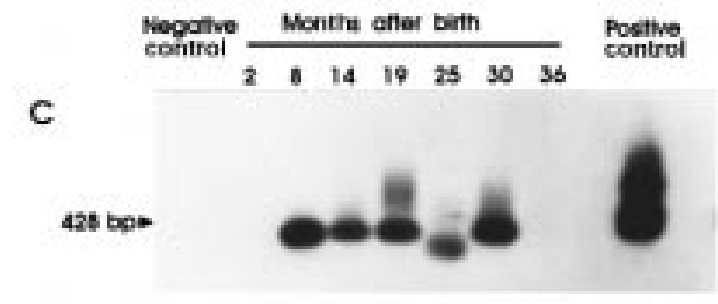

s

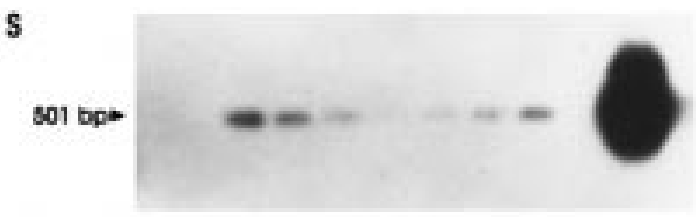

$\mathrm{x}$

193 bpt tion of the test RNA by RT-PCR in which enzyme (RT) was omitted. To determine whether detection of these transcriptionally active virus genomes can be enhanced, we took advantage of previous observations that mitogen stimulation increases WHV transcription and production of infectious virions by PBMCs from WHsAg-positive chronic carriers and woodchucks convalescent from $\mathrm{AH}$ $(19,27)$. Results were compared with WHV RNA detection in nonstimulated PBMCs obtained from the same blood sample. As shown in Figure 3b, ConA stimulation of PBMCs from 11D/F enabled detection of viral mRNA, although nonstimulated cells were apparently nonreactive for WHV RNA. Similar results were seen after culture of PBMCs from 8D/M and 9D/F with LPS (data not shown).

To determine whether mitogen-stimulated PBMCs from offspring secrete WHV, expression of virus genome was evaluated in both the concentrated final washes from the PBMCs before their culture and in the concentrated culture supernatant from cells stimulated with LPS for 72 hours. Although WHV DNA was not detected in the washes, all PBMC culture supernatant tested positive (data not shown). In other experiments, the culture supernatant from the mitogen-stimulated PBMCs

\section{Figure 2}

Detection of WHV cccDNA in selected WHV DNA-reactive liver, PBMCs, and lymphoid tissue samples from 3B/M, 4B/M, and 5C/F offspring. DNA was extracted from autopsy spleen and bone marrow of $3 B / M$; from liver biopsies collected at 19 and 31 months and PBMCs obtained at 34 and 41 months after birth from $4 \mathrm{~B} / \mathrm{M}$; and from liver, spleen, and bone marrow collected at autopsy of 5C/F performed at 22 months of age. The PBMCs harvested from $4 B / M$ at 41 months after birth were extensively washed and the cell surface treated with DNase and trypsin before DNA isolation. DNA samples $(2$ or $5 \mu \mathrm{g}$ ) were digested with mung bean endonuclease and subjected to nested PCR with primers amplifying the WHV gap-spanning region. DNA samples from a WHsAg-positive chronic carrier were included as positive controls; water instead of DNA and a mock sample extracted in parallel with test samples were used as negative controls. Positive samples showed the expected size of the amplified nucleotide fragments indicated on the left.

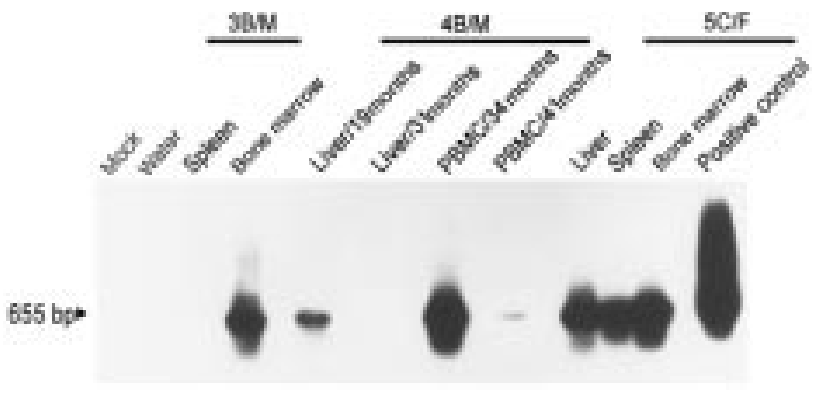

The Journal of Clinical Investigation $\quad$ July 1999 | Volume 104 | Number 2 


\section{Figure 3}

Identification of WHV RNA sequences in naive and mitogen-stimulated PBMCs in offspring born to mothers convalescent from viral hepatitis. Total RNA was extracted from (a) unstimulated PBMCs from 4B/M offspring obtained at 18,30 , and 32 months after birth and from (b) unstimulated (-ConA) and Con A-stimulated (+ConA) PBMCs from $11 \mathrm{D} / \mathrm{F}$ offspring at 34.5 months after birth. RNA isolated from Con A-stimulated PBMCs of a WHV-negative, healthy woodchuck (Control PBMCs + ConA) and from the spleen of a WHsAg-positive chronic WHV carrier (Positive control) was used as control. For all RT reactions, cDNA synthesis was carried out by RT (RT+) and the cDNA analyzed by nested PCR/Southern blot hybridization. Each RNA sample was subjected to the same reaction conditions in the absence of RT (RT-).

was also analyzed to determine physicochemical properties and infectivity of WHV DNA-reactive particles (see discussion later here).

Variable patterns of WHV genome expression in offspring liver. All liver samples from the offspring were tested for WHV DNA by nested PCR with primers specific for WHV C, S, and $\mathrm{X}$ genes and by Southern blotting (approximate sensitivity: 0.02 WHV vge $/ 10^{4}$ cells). Based on the status of WHV genome expression in the liver before WHV challenge, the offspring were classified into 3 groups. In the first group, which included 6 animals $(2 \mathrm{~B} / \mathrm{F}, 5 \mathrm{C} / \mathrm{F}, 6 \mathrm{D} / \mathrm{F}$, $8 \mathrm{D} / \mathrm{M}, 10 \mathrm{D} / \mathrm{F}$, and $11 \mathrm{D} / \mathrm{F}), \mathrm{WHV}$ genomes were detected in all liver samples. Lymphoid tissues obtained at autopsy of 2 of these animals (2B/F and 5C/F) were also found to be reactive for WHV DNA and mRNA (data not shown). In addition, WHV cccDNA was found in autopsy liver, spleen, and bone marrow of 5C/F (Figure 2). Evaluation of WHV DNA in liver samples from 4 other animals $(1 \mathrm{~A} / \mathrm{F}, 3 \mathrm{~B} / \mathrm{M}, 7 \mathrm{D} / \mathrm{F}$, and $9 \mathrm{D} / \mathrm{F})$ rendered an unexpected result. In these offspring, the virus was not detected in the liver despite repeated testing, even when 2 of these offspring $(7 \mathrm{D} / \mathrm{F}$ and $9 \mathrm{D} / \mathrm{F})$ were tested as late as $22-23$ months after birth. Most interestingly, PBMCs from $3 \mathrm{~B} / \mathrm{M}$ (Figure 4) and from $7 \mathrm{D} / \mathrm{F}$ and $9 \mathrm{D} / \mathrm{F}$ obtained before WHV challenge (data not shown), as well as autopsy lymphoid tissue from $1 \mathrm{~A} / \mathrm{F}$ (data not shown) and $3 \mathrm{~B} / \mathrm{M}$ (Figure 4), carried WHV genomes. Figure 4 illustrates an example of lymphoid tissue-restricted WHV DNA expression in 3B/M observed for 15 months after birth. In 2 liver samples from this animal, obtained at 6 and 15 months after birth, WHV DNA was repeatedly nonreactive by nested PCR using C, S, and X gene primers and by subsequent hybridization analysis (Figure 4 and data not shown). In contrast, WHV DNA was readily detectable in the spleen, bone marrow, and lymph nodes (Figure 4), and WHV

\section{Figure 4}

Analysis of WHV DNA expression in liver, PBMCs, and lymphoid tissues collected from 3B/M offspring. WHV gene sequences were identified by nested $P C R$ using $C$ and $X$ gene-specific primers, followed by Southern blot hybridization of the amplified products to recombinant WHV DNA. Five micrograms of DNA extracted from liver samples collected at 6 months of age and at autopsy performed at 15 months after birth, and $1 \mu \mathrm{g}$ DNA from PBMCs collected at 14.5 months of age and from spleen, lymph node, bone marrow, and skeletal muscle obtained at autopsy, were used for direct PCR amplification. Positive samples showed the expected molecular size of the amplified virus $C$ and $X$ gene fragments indicated on the left. a

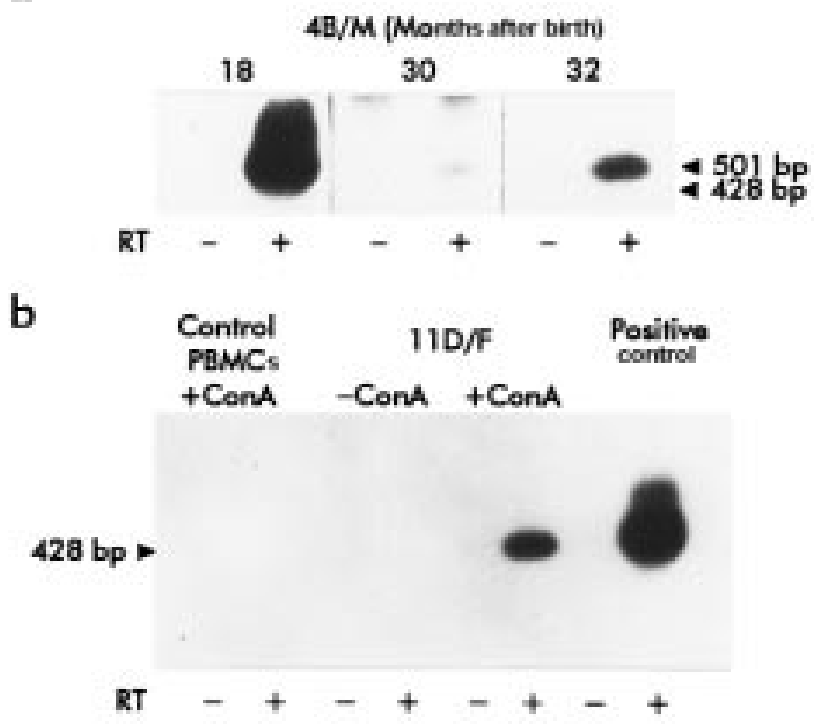

RNA was readily detectable in the spleen of this animal, as were traces of WHV cccDNA in the bone marrow (Figure 2). A third pattern of hepatic WHV DNA expression was observed in $4 \mathrm{~B} / \mathrm{M}$. In this animal, WHV DNA was not detected in the first biopsy collected at 6 months after birth, but a subsequent biopsy obtained at 19 months was reactive for both WHV DNA (data not shown) and WHV cccDNA (Figure 2), whereas a third biopsy taken at 31 months tested WHV DNA positive (data not shown). These findings document that long-term persistence of hepadnavirus can be maintained exclusively at an extrahepatic location and that, under certain natural conditions, infection of the liver may occur months after initial exposure to WHV. Histology showed normal hepatic morphology in all investigated offspring.

Complete sequence analysis of the WHV S gene, and partial sequencing of the C gene in WHV DNA isolated from the spleen of a WHV DNA-negative offspring $(3 \mathrm{~B} / \mathrm{M})$ and the liver of a WHV DNA-positive offspring (4B/M; liver biopsy obtained at 19 months of age), did not reveal any alterations, compared with the wild-type WHV sequences that were detected in 2 liver biopsies collected from their mother (B) before and after parturition.

Physicochemical properties of WHV DNA-reactive particles carried by offspring. To assess whether WHV DNA is contained within virion particles, the sedimentation velocity and buoyant density of WHV DNA-reactive molecules occurring in offspring sera and PBMC culture supernatant were compared with those of purified WHV viri-

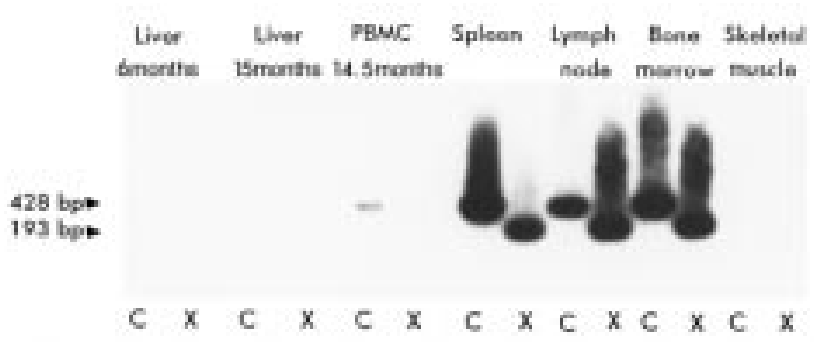




\section{Figure 5}

Effect of DNase digestion on WHV DNA-reactive particles circulating in an offspring born to a mother convalescent from viral hepatitis. Serum obtained at 32 months after birth from 4B/M offspring with WHV DNA expression in both liver and PBMCs; purified WHV virions; and Mnlldigested recombinant WHV DNA were centrifuged through 15\% sucrose over a $60 \%$ sucrose cushion, as described in Methods. Fifteen fractions collected from the bottom of each gradient were tested for WHV DNA by PCR, and those showing highest WHV DNA reactivity were pooled and were digested with $\mathrm{DNase}(\mathrm{D})$. Tested samples included pooled fractions 1-3 (bottom) for WHV virions, 1-5 (bottom) and 8-12 (top) for 4B/M serum, and 9-11 (top) for recombinant WHV DNA. As controls, samples of the same pooled fractions, but this time not treated with DNase (ND), were used. DNA extracted from each sample was tested for WHV S gene sequences by nested PCR and Southern blot hybridization.

ons. For these evaluations, samples from $4 \mathrm{~B} / \mathrm{M}$ and $7 \mathrm{D} / \mathrm{F}$ were chosen because the animals displayed opposite status of WHV genome expression in the liver at the time of examination. After sucrose centrifugation of the offspring sera, 2 peaks of WHV DNA reactivity were detected. The first peak (bottom fractions 1-5) corresponded to WHV DNA-positive fractions 1-3 of complete WHV virions. The second peak (fractions 8-12) corresponded to WHV DNA-positive fractions 9-11 recovered after centrifugation of recombinant $\mathrm{MnlI}$ digested WHV DNA. These findings suggest that WHV DNA-reactive molecules detected in offspring sera exhibited properties of both intact (complete) virions and WHV DNA fragments. Furthermore, the bottom fractions collected after centrifugation of $4 \mathrm{~B} / \mathrm{M}$ serum or WHV virions (control) remained reactive for WHV DNA after DNase treatment (Figure 5), supporting the existence of an envelope-protected virus genome. Conversely, the same DNase treatment of fractions harvested from the upper part of $4 \mathrm{~B} / \mathrm{M}$ serum and recombinant WHV DNA gradients entirely eliminated WHV DNA reactivity, indicating the presence of fragmented WHV DNA. In addition, the buoyant densities of WHV DNA-reactive molecules in serum collected at 22 months of age from $7 \mathrm{D} / \mathrm{F}$, and in serum and culture supernatant of mitogen-stimulated PBMCs obtained at 32 months after birth from 4B/M, were analyzed, as were purified WHV virions. PCR testing of fractions from the virion gradient revealed viral DNA in fractions 9-13, with a mean $\mathrm{CsCl}$ density of $1.25 \mathrm{~g} / \mathrm{cm}^{3}$. Similarly, sera and a PBMC-derived culture supernatant from 4B/M and $7 \mathrm{D} / \mathrm{F}$ showed WHV DNA reactivity in fractions $8-13$, with mean buoyant density of $1.26 \mathrm{~g} / \mathrm{cm}^{3}$ (data not shown). This finding is further evidence that intact WHV virions circulated long after birth in the offspring born to dams that were apparently healthy after resolution of hepatitis.

Infectivity of WHV carried by offspring. To determine whether the offspring carried infectious WHV, plasma and PBMC-derived inocula from 4B/M (when the liver was WHV DNA positive) were injected into WHV-naive woodchucks 269/F and 278/F, respectively. In a supplementary experiment, inocula prepared from serum or plasma of liver WHV DNA-nonreactive 3B/M and 7D/F were administered to $260 / \mathrm{M}$ and $276 / \mathrm{F}$, respectively. Naive animals 269/F and 278/F, injected with materials from $4 \mathrm{~B} / \mathrm{M}$, developed typical WHsAg- and anti-

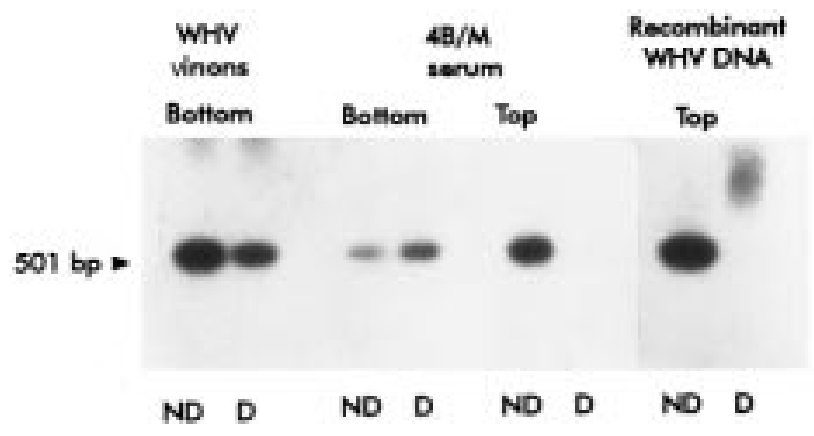

WHc-positive transient $\mathrm{AH}$, followed by persistence of WHV DNA traces both in the liver and lymphatic system. Liver biopsies obtained 2.5 months after inoculation showed histological features of AH in 269/F and mild inflammatory changes consistent with residual AH in $278 / F$. Analysis of complete WHV genome in the autopsy liver, spleen, and serum from these 2 animals revealed wild-type virus (data not shown). These findings clearly demonstrated that pathogenic virus continued to replicate in $4 \mathrm{~B} / \mathrm{M}$ for more than 2.5 years after birth. In contrast, inocula prepared from liver WHV DNA-nonreactive $3 \mathrm{~B} / \mathrm{M}$ and $7 \mathrm{D} / \mathrm{F}$ induced an occult WHV infection in $260 / \mathrm{M}$ and $276 / \mathrm{F}$ that was characterized by the persistence of minute amounts of WHV genomes circulating in the absence of WHsAg and anti-WHc. Furthermore, autopsy lymphoid tissues from both 260/M and $276 / F$, as well as autopsy liver from $276 / F$, were WHV DNA positive. In contrast, 2 liver samples taken from 260/M at 70 and 110 days after inoculation were invariably nonreactive for WHV DNA, even when $5 \mu \mathrm{g}$ of total DNA was tested (Figure 6). All liver samples from 260/M

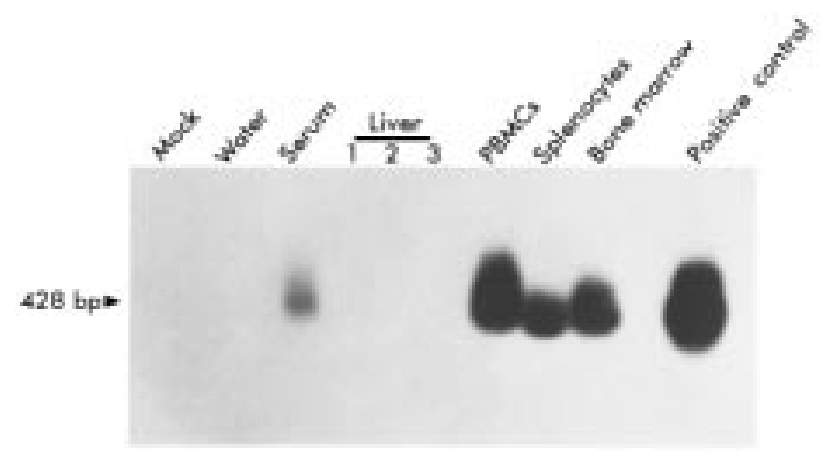

Figure 6

WHV DNA expression in serum, liver, and lymphoid cells of 260/M woodchuck after inoculation with serum from liver WHV DNA-negative 3B/M offspring. Five micrograms of total DNA from liver biopsies collected at $\sim 2$ months before (1) and 2 months after (2) inoculation and at autopsy (3), and $1 \mu \mathrm{g}$ of DNA from autopsy PBMCs, isolated splenocytes, and bone marrow obtained at 3.5 months after inoculation or from $50 \mu \mathrm{L}$ of autopsy serum, were tested for WHV DNA by nested PCR using WHV C gene-specific primers and hybridization to WHV DNA probe. DNA from serum of a WHsAg-positive chronic carrier was included as a positive control, and water instead of DNA and a mock sample extracted in parallel with test samples were used negative controls. Positive samples showed the expected 428-bp nucleotide fragment noted by arrowhead. 
had normal morphology, whereas autopsy liver from 276/F showed minimal changes consisting of lymphomononuclear infiltrations in singular portal areas and around single degenerating hepatocytes.

Offspring born to convalescent mothers remain susceptible to WHV infection. Four offspring (6D/F, 7D/F, 8D/M, and 9D/F) were challenged with a massive WHV dose $(1.1 \times$ $10^{10}$ vge). After challenge, serum WHV DNA levels increased by 10 - to 100 -fold from day 14 to day 42 after inoculation and then dropped to preinoculation levels (data not shown). WHsAg was detected transiently between days 35 and 42 after inoculation in $9 \mathrm{D} / \mathrm{F}$, and anti-WHs was detected at dpl 82 in 6D/F. All challenged animals developed anti-WHc and, except 6D/F, remained anti-WHc positive until the end of follow-up. Autopsy liver and lymphoid tissues from $6 \mathrm{D} / \mathrm{F}$ were reactive for WHV DNA and WHV mRNA (data not shown). Liver samples obtained 6-12 months after challenge had normal histology in $6 \mathrm{D} / \mathrm{F}$ and $7 \mathrm{D} / \mathrm{F}$ or features of residual liver inflammation in $8 \mathrm{D} / \mathrm{M}$ and $9 \mathrm{D} / \mathrm{F}$. In general, offspring injected with a high virus dose developed transient, serologically evident hepatitis independent of whether they expressed $(6 \mathrm{D} / \mathrm{F}$ and $8 \mathrm{D} / \mathrm{M})$ or did not express $(7 \mathrm{D} / \mathrm{F}$ and 9D/F) WHV DNA in the liver before the challenge.

\section{Discussion}

We have shown that dams with complete recovery from viral hepatitis, manifested by seroconversion to antiWHs and normalization of liver histology, transmit virus to newborns. The induced infection is asymptomatic, progresses for years after birth in the absence of serum WHsAg or anti-WHs and anti-WHc antibodies, and is characterized by small quantities of WHV genomes in the circulation, lymphatic tissue, and usually, but not always, in the liver. In other studies, it has been documented that exposure to virus in early development often results in lifelong viral persistence (28). Previous findings in adult woodchucks convalescent from $\mathrm{AH}$ (19) and in patients with complete clinical and serological recovery from acute HBV infection $(4,7)$ showed long-term persistence of virus genomes accompanied by circulating anti-WHc and anti-HBc antibodies, respectively. In contrast to convalescent adult woodchucks, anti-WHc antibodies were never detected in the offspring in this study, unless the animals were challenged with WHV. In these offspring, WHV genomes persisted up to 3.5 years after birth at levels of $10-100$ $\mathrm{vge} / \mathrm{mL}$ of serum and $0.05-5.0 \mathrm{vge} / 10^{4}$ circulating and organ lymphoid cells. In WHV DNA-reactive offspring livers, the estimated number of WHV genomes detected at the end of the observation period was $0.2-20 \mathrm{vge} / 10^{4}$ cells. These WHV loads were comparable to those in adult animals years after recovery from $\mathrm{AH}$, including dams of the offspring investigated (19). In some of these woodchucks, the persistence of virus traces was ultimately accompanied by the development of hepatocellular carcinoma (19).

Transcriptionally competent WHV sequences were detected in circulating lymphomononuclear cells and/or lymphoid organs from all offspring studied. The conclusion that the offspring lymphoid cells carried WHV was based on the following findings: (a) WHV DNA and
WHV cccDNA were identifiable in PBMCs treated with DNase/trypsin to remove any potentially adsorbed viral DNA; (b) WHV DNA was detected in PBMCs from serum WHV DNA-negative blood samples collected long after birth; (c) both WHV DNA- and mRNA-specific sequences were detectable in the same PBMCs and lymphoid organs for up to 3.5 years after birth; (d) mitogen stimulation of PBMCs from the late phase of followup enhanced WHV mRNA expression, demonstrating that the apparently nonreactive cells in fact contained transcriptionally active viral genomes; and (e) secretion of WHV DNA-reactive particles behaving as intact virions by mitogen-stimulated PBMCs, and demonstration that they were infectious, conclusively documented that the lymphoid cells contained biologically competent virus long after birth.

Involvement of the host lymphatic system in hepadnavirus infection has been demonstrated in previous reports. WHV DNA and RNA have been identified in PBMCs and lymphatic organs of woodchucks with WHsAg-reactive chronic hepatitis $(29,30)$ and in convalescent animals shortly after seroconversion to anti-WHs (31). In our laboratory, pathogenic virus has been documented in lymphoid cells throughout the life-span of woodchucks after apparent complete recovery from $\mathrm{AH}$ (19). It has also been shown that the preS1 domain of the WHV envelope is endowed with a cell-binding site that recognizes lymphoid cells and hepatocytes in a strictly cell- and species-specific manner (21). Synthetic analogues of this cell-binding site interact to a considerably greater extent with woodchuck lymphoid cells than with hepatocytes, suggesting that lymphoid cells could be the preferable targets for WHV invasion. This possibility appears to be supported by the present observation of persistent WHV transcription restricted to the lymphatic system. Thus, WHV genomes were found in PBMCs and lymphoid organs, but not livers, of 4 of the offspring studied. This unexpected finding was confirmed by repeated nested PCR/Southern blot analysis of multiple DNA preparations from these livers. In contrast, WHV genomes, transcripts, and cccDNA were identifiable in lymphoid cells from the same animals. Therefore, our study documents that under certain natural conditions, the cells of the lymphatic system can support hepadnavirus replication in the context of the complete, longterm absence of the virus in the liver.

Offspring born to the same maternal woodchuck had different tissue patterns of WHV expression. For example, 7D/F and 9D/F born to D mother did not have any detectable WHV DNA in sequential liver biopsies obtained before WHV challenge, yet the viral genome could be detected in livers of 4 other offspring from the same litter (6D/F, 8D/M, 10D/F, and 11D/F). Unfortunately, we could not obtain liver samples from these animals until 6 months after birth. Therefore, we cannot completely rule out the possibility that the liver had initially been positive but then cleared the virus. We do not believe, however, that this was the case, as even a liver sample collected at 1 month after birth $(1 \mathrm{~A} / \mathrm{F})$ was found to be negative for WHV DNA. In addition, we have never observed WHV clearance from the liver of any WHVinfected woodchuck that had been previously found to 
be reactive for liver WHV DNA (19). In contrast, there was a case $(4 \mathrm{~B} / \mathrm{M})$ that initially had a lymphoid-restricted WHV infection but at 19 months after birth became reactive for liver WHV DNA. Because all of these offspring were born to the same mother, it is likely that an unidentified host factor influenced organ tropism.

To determine whether WHV DNA detected in offspring sera and in a supernatant from mitogen-stimulated PBMCs could reflect the existence of intact WHV virions, physicochemical properties of WHV DNA-reactive molecules were analyzed. This study showed that some of the WHV DNA particles occurring in offspring sera migrated in sucrose gradients with a velocity identical to that of virions and were resistant to DNase digestion, providing strong evidence for the existence of intact virus. Furthermore, centrifugation in $\mathrm{CsCl}$ gradients indicated that WHV DNA-reactive particles in the offspring sera and in a PBMC culture supernatant exhibited buoyant densities that corresponded to those of complete WHV. These findings are comparable to those obtained from analysis of sera from individuals who apparently completely recovered from AH type B (4). Definitive proof for the presence of biologically competent virus in the offspring was obtained by demonstration of WHV transmission to healthy animals. Normal woodchucks injected with concentrated plasma and PBMC supernatant from a liver WHV DNA-positive (4B/M) offspring developed WHsAg- and anti-WHc-positive, histologically evident $\mathrm{AH}$ that bore WHV sequences indistinguishable from those of the wild virus. Therefore, it was conclusively documented that intact pathogenic virus persisted in this offspring despite serum WHsAg negativity.

Most interestingly, inocula from liver WHV DNA-nonreactive $(3 \mathrm{~B} / \mathrm{M}$ and $7 \mathrm{D} / \mathrm{F})$ offspring induced asymptomatic, WHsAg- and anti-WHc-negative infection characterized by the presence of small quantities of WHV DNA both in lymphoid tissues and in the circulation, but not always (i.e., 260/M) in the liver. Because comparable amounts of WHV genomes were present in inocula prepared from either liver WHV DNA-reactive or -nonreactive offspring, we do not think that the serologically occult infection observed in 260/M and 276/F was related to the amount of virus injected. So far, partial sequence analysis of splenic WHV DNA from a livernegative $(3 \mathrm{~B} / \mathrm{M})$ offspring, from which serum test inoculum was derived, did not show any sequence variation in comparison to sequences of hepatic WHV DNA from livers of WHV DNA-positive (B and 4B/M) woodchucks. Certainly, additional studies will be required to clarify whether viral mutants with preferable or exclusive tropism for lymphoid cells exist and contribute to generation of serologically occult infection.

Offspring were not protected from WHV reinfection, and they developed a serologically transient hepatitis independent of whether or not they expressed WHV DNA in the liver before WHV challenge. This contrasts with our previous observations in adult woodchucks convalescent from $\mathrm{AH}$ that persistently carried comparably low levels of WHV yet were unresponsive to challenge with the same WHV pool (19). The apparent discordance between the persistent replication of competent virus at minuscule levels in the neonatally infected animals, susceptibility of the offspring to reinfection with a large dose of WHV, and their ability to terminate this superinfection swiftly might be explained by assuming that transmission of small amounts of virus in early life induces an amnestic immune response that is sufficient to control (but not eradicate) a low-level infection yet is not strong enough to protect against a massive WHV dose. Simultaneously, owing to continuous encounter, the immune system may have adequate recollection of virus to mount a vigorous response capable of limiting liver disease induced by the superinfection. The existence of this amnesic protection could be considered, because inoculation of $10 \mathrm{D} / \mathrm{F}$ with a low virus dose $\left(\sim 3 \times 10^{3}\right.$ WHV genomes) derived from PBMCs (Table 1) did not produce superinfection (but did stimulate anti-WHs), although a similar inoculum caused classical AH in WHV-naive adult woodchucks (19). To test this hypothesis, a series of WHV-naive woodchucks injected with decreasing doses of WHV could be used to assess whether virus traces will induce infection in a manner comparable with that found in the present study, and, if so, whether challenge with low or high virus doses influences the outcome of superinfection. Extensive work will be required to complete this adjunct investigation.

Although the mode of maternal transmission of hepadnavirus from mother to offspring might differ in humans and woodchucks, significant pathobiological similarities between HBV and WHV raise the possibility that HBV can also be vertically transmitted from apparently healthy mothers convalescent from hepatitis B to their babies. Consequently, infants born to these mothers may persistently carry small amounts of infectious virus and may possibly have an increased long-term risk for the development of liver and extrahepatic disorders that are currently not known to be caused by HBV. They may also represent a potential reservoir of virus for infection of healthy individuals.

\section{Acknowledgments}

We thank Norma D. Churchill, Ingrid U. Pardoe, and Colleen L. Trelegan for their excellent technical assistance; Luke Grenning for surgical assistance; and Judy Foote and Edward Evelly for preparation and staining of paraffin sections. This work was supported by operating grants MT-11262 and MT-14818 from the Medical Research Council of Canada (to T.I. Michalak). C.S. Coffin is a recipient of a Graduate Studentship Award from the Canadian Liver Foundation.

\footnotetext{
1. Mazzur, S., and Blumberg, B.S. 1974. Silent maternal transmission of Australian antigen. Nature. 247:41-43.

2. Beasley, R.P., Hwang, L.Y., Lin, C.C., and Chien, C.S. 1981. Hepatocellular carcinoma and hepatitis B virus. A prospective study of 22,707 men in Taiwan. Lancet. 2:1129-1133.

3. Blum, H.E., Liang, T.J., Galum, E., and Wands, J.R. 1991. Persistence of hepatitis B viral DNA after serological recovery from hepatitis B virus infection. Hepatology. 14:56-63.

4. Michalak, T.I., Pasquinelli, C., Guilhot, S., and Chisari, F.V. 1994. Hepatitis B virus persistence after recovery from acute viral hepatitis. J. Clin. Invest. 93:230-239.

5. Penna, A., et al. 1996. Long-lasting memory T cell responses following self-limited acute hepatitis B. J. Clin. Invest. 98:1185-1194.

6. Rehermann, B., et al. 1995. The cytotoxic T lymphocyte response to mul-
} 
tiple hepatitis B virus polymerase epitopes during and after acute viral hepatitis. J. Exp. Med. 181:1047-1058.

7. Rehermann, B., Ferrari, C., Pasquinelli, C., and Chisari, F.V. 1996. The hepatitis B virus persists for decades after patients' recovery from acute viral hepatitis despite active maintenance of a cytotoxic T-lymphocyte response. Nat. Med. 2:1104-1108.

8. Yotsuyanagi, H., et al. 1998. Persistent viremia after recovery from selflimited acute hepatitis B. Hepatology. 27:1377-1382.

9. Chazouillères, O., et al. 1994. "Occult" hepatitis B virus as source of infection in liver transplant recipients. Lancet. 343:142-146.

10. Lowell, J.A., et al. 1995. Serological evidence of past hepatitis B infection in liver donors and hepatitis B infection in liver allografts. Lancet. 345:1084-1085.

11. Wachs, M.E., et al. 1995. The risk of transmission of hepatitis B from $\mathrm{HBsAg}(-), \mathrm{HBcAb}(+), \operatorname{HBIgM}(-)$ organ donors. Transplantation. 59:230-234.

12. McIvor, C., et al. 1994. Fatal reactivation of precore mutant hepatitis B virus associated with fibrosing cholestatic hepatitis after bone marrow transplantation. Ann. Intern. Med. 121:274-275.

13. Martin, P., and Friedman, L.S. 1995. Chronic viral hepatitis and the management of chronic renal failure. Kidney Int. 47:1231-1241.

14. Liang, T.J., Blum, H.E., and Wands, J.R. 1990. Characterization and biological properties of a hepatitis B virus isolated from a patient without hepatitis B virus serologic markers. Hepatology. 12:204-212.

15. Paterlini, P., et al. 1990. Polymerase chain reaction to detect hepatitis B virus DNA and RNA sequences in primary liver cancers from patients negative for hepatitis B surface antigen. N. Engl. J. Med. 323:80-85.

16. Lai, M.Y., et al. 1990. Identification and characterization of intrahepatic hepatitis B virus DNA in HBsAg-seronegative patients with chronic liver disease and hepatocellular carcinoma in Taiwan. Hepatology. 12:575-581.

17. Tennant, B.C., and Gerin, J.L. 1994. The woodchuck model of hepatitis $B$ virus infection. In The liver: biology and pathobiology. I.M. Arias et al., editors. Raven Press. New York, NY. 1455-1466.

18. Michalak, T.I. 1998. The woodchuck animal model of hepatitis B. Viral Hepat. Rev. 4:139-165

19. Michalak, T.I., et al. 1999. Occult lifelong persistence of infectious hepadnavirus and residual liver inflammation in woodchucks convalescent from acute viral hepatitis. Hepatology. 29:928-938.

20. Michalak, T.I., Churchill, N.D., Codner, D., and Marshall, W.H. 1995.
Identification of woodchuck class I MHC antigens using monoclonal antibodies. Tissue Antigens. 45:333-342.

21. Jin, Y-M., Churchill, N.D., and Michalak, T.I. 1996. Protease-activated lymphoid cell and hepatocyte recognition site in the preS1 domain of the large woodchuck hepatitis virus envelope protein. J. Gen. Virol. 77:1837-1846.

22. Michalak, T.I., Snyder, R.L., and Churchill, N.D. 1989. Characterization of the incorporation of woodchuck hepatitis virus surface antigen into hepatocyte plasma membrane in woodchuck hepatitis and in the virusinduced hepatocellular carcinoma. Hepatology. 10:44-55.

23. Pardoe, I.U., and Michalak, T.I. 1995. Detection of hepatitis B and woodchuck hepatitis viral DNA in plasma and mononuclear cells from heparinized blood by the polymerase chain reaction. J. Virol. Methods. 51:277-288.

24. Kodoma, K., Ogasawara, N., Yoshikawa, H., and Murakami, S. 1985. Nucleotide sequence of a cloned woodchuck hepatitis virus genome: evolutional relationship between hepadnaviruses. J. Virol. 137:390-399.

25. Gunther, S., et al. 1995. A novel method for efficient amplification of whole hepatitis B virus genomes permits rapid functional analysis and reveals deletion mutants in immunosuppressed patients. J. Virol. 69:5437-5444.

26. Michalak, T.I., and Lin, B. 1994. Molecular species of hepadnavirus core and envelope polypeptides in hepatocyte plasma membrane of woodchucks with acute and chronic viral hepatitis. Hepatology. 20:275-286.

27. Korba, B.E., Cote, P.J., and Gerin, J.L. 1988. Mitogen-induced replication of woodchuck hepatitis virus in cultured peripheral blood lymphocytes. Science. 241:1213-1216.

28. Ahmed, R. 1989. Immunological tolerance in viral infections. In Concepts in viral pathogenesis III. A.L. Notkins and M.B.A. Oldstone, editors. Springer-Verlag. New York, NY. 302-310.

29. Korba, B.E., Wells, F., Tennant, B.C., Cote, P.J., and Gerin, J.L. 1987. Lymphoid cells in the spleens of woodchuck hepatitis virus-infected woodchucks are a site of active viral replication. J. Virol. 61:1318-1324.

30. Chemin, I., et al. 1992. Demonstration of woodchuck hepatitis virus infection of peripheral blood mononuclear cells by flow cytometry and polymerase chain reaction. J. Gen. Virol. 73:123-129.

31. Korba, B.E., et al. 1989. Hepatocellular carcinoma in woodchuck hepatitis virus-infected woodchucks: presence of viral DNA in tumour tissue from chronic carriers and animals serologically recovered from acute infection. Hepatology. 9:461-470. 